\title{
Process of precocious functional aging in workers of laundries
}

\author{
Simone Caldas Tavares Mafra ${ }^{\mathrm{a}, 1}$, Celina Angélica Lisboa Valente Carlos ${ }^{\mathrm{b}}$ e Vania Eugênia da Silva ${ }^{\mathrm{c}}$ \\ ${ }_{a, b, c}$ Departament of Home Economics, Federal University of Vicosa, Vicosa, State of Minas Gerais, Brazil
}

\begin{abstract}
The World Health Organization (WHO), as well as researchers of the whole world, it has been demonstrating concern with the subject of the aging related to the work and it recognizes that modifications in the several systems of the human body take to the gradual decrease in the effectiveness of each one of them, because the aging caused by the work advances apprenticeships of the cycle of the man's life, not respecting the natural state of that process. In this sense, it was aimed at with this research to investigate the relative aspects to the capacity for the work and to the workers' with responsibility to realize the work in the laundries service, verifying if they present signs of precocious functional aging.
\end{abstract}

Keywords: Capacity for the work; Precocious functional aging; Laundry; Workers.

\section{Introduction}

Several transformations in the job market and in the productive processes of services rendered they have been happening all over the world. To deterioration of the work conditions it is also observed in their new organization forms, to make flexible of their days, in the precarious conditions of work and in the crescent underemployment, especially concerning the hand of work outsourced and in the temporality of the contracts, taking to the workers' constant change (FISCHER et al., 2005).

In those conditions, diseases have been attacking many workers in productive age, breaking the balance health-productivity and, consequently, offer damages not only for the own worker, but also for the company and to the country as an all seen such events modify in the condition of population offer economically active (PIZZATO, 2002).

The bad life conditions can cause psychological and physiologic wear and tear in the worker's life, increasing the functional aging, with repercussions in the social life and family.

Like this, the organization of the work environment is fundamental for the well-being, the comfort, the safety and the worker's health. However, it is known that a great number of work environments is found inadequate conditions, as high temperature, noise excessive, bad illumination, furnitures and equipments in bad conditions and repetitive activities that involve overload postural.

In that way, this study was developed with the objective of investigating the capacity for the work and the workers' of laundries health, as well as to verify these workers presents signs of precocious functional aging.

\section{Procedures}

This study was accomplished at two laundries of the metropolitan area of Belo Horizonte, state of Minas Gerais, Brazil and two in the area of the Juiz de Fora, in the same state. Among the services offered in those cities stands out the one of laundries.

The laundries were denominated: 1 and 2 (located laundries in the metropolitan area of Belo Horizonte), 3 and 4 (located laundries in the area of the Juiz de Fora).

The laundry 1 from creation it rendered administration services and process of laundry services, as lease of laundry services and of sterilization for areas hospitalares, hotel, motel and industry. It possessed

1 a 1 sctmafra@ufv.br; ${ }^{\mathrm{b}}$ celinavalente@yahoo.com.br; ${ }^{\mathrm{c}}$ vaeusi@yahoo.com.br 
at that time, in the city of Belo Horizonte, about 70 employees.

The laundry 2 realyse the process of laundry services considering hospital, motel and hotel clothes. This laundry counted with about 122 employees, that they were entrusted of transporting the clothes, the process of laundry and to return them in perfect use conditions to the plaintiffs.

The laundry 3 had as main activity branch, the jeans wash and other kind of textiles, besides accomplishing improvement processes in the jeans, assisting 46 industries of Juiz de Fora and region.

The laundry 4 worked with jeans wash, other kind of textiles, for example, and other fabrics assisting local makings, of Juiz de Fora and region.

The sample of this study was constituted by workers that worked there are more than one year at the laundries and that were put available and interested parties in participating in the research. Like this, 69 workers assisted to the requirements put in the beginning of the work.

The first phase consisted of interview with the supervisors of human resources of the laundries. In the second phase took place no structure interviews with the workers of the laundries, using adapted instrument and proposed for Odebrecht (2002). In this instrument, referred author looks for to analyze the work environment, the worker's psychological profile and aging apprenticeship considering the indicators of the respective instrument. To tabulate the data of the interview the program Statistical Package it was used is Social Sciences (SPSS).

Already in the third phase it was made measurement of the temperature and noise in the four laundries, being used specific equipments, as measured of IBUTG: the measurements were accomplished during a period of three hours, in the laundries 1 and 2 . In the laundries 1 and 3, the equipment was close to the presses and in the laundry 2, close to the skylarks. In the laundry 4, the apparel was close to the drying ones. Dosimeter: the measurement accomplished with the dosimeter had duration of $5 \mathrm{~h} 30 \mathrm{~min}$. in the laundries 1 and 2. They were chosen workers of the skylark and of the drying for us to be with the dosebadges.

In the laundries 3 and 4, the decibilimeter was used that also accomplishes measurements of the noise levels. Those measurements were made in the environment of 30 in 30 minutes. and had duration of eight hours, regarding the work shift. The data generated by the dosimeter were confronted with Regula- mentatory Roles number 15 (NR-15) that treats of activities and unhealthy operations.

In the fourth phase they were identified and analyzed the medical certificates presented to the companies by the workers as justification for the lacks. The information contained in the certificates were confronted with the CID-10 (International Code of Diseases) of Ministry of Health of Brazil.

In the fifth phase took place observation noparticipant, aiming at larger interaction with the workers, to know the work routine, looking for in those, larger subsidy for analysis of the data gotten to field, considering those that involve the workers' perception on health and work. Finally, in the sixth phase, it was looked for to analyze the data and to discuss their results, looking for, at the end, subsidies, to conclude the study, as well as to answer to the proposed objective.

\section{Results and Discussion}

\subsection{Evaluation of the thermal environment}

The temperature indexes found at the fourth laundries were, respectively: $\left(22.9^{\circ} \mathrm{C}\right.$ a $\left.48.2^{\circ} \mathrm{C}\right) ;\left(20.9^{\circ} \mathrm{C}\right.$ a $\left.42.1^{\circ} \mathrm{C}\right)$; $\left(21^{\circ} \mathrm{C}\right.$ a $\left.26^{\circ} \mathrm{C}\right)$ e $\left(21.6^{\circ} \mathrm{C}\right.$ a $\left.26.7^{\circ} \mathrm{C}\right)$. The temperature index recommended by NR-15 is of up to $26.7^{\circ} \mathrm{C}$. For Couto (1995) to expose the worker at high temperatures, when in task execution, it can cause diseases.

When the man is forced to support high temperatures, income falls, the speed of the work decreases, the pauses become larger and more frequent, the concentration degree decreases and the frequency of mistakes or accidents it tends to increase too, above all starting from the $30^{\circ} \mathrm{C}$ (FIEDLER et al., 2006).

Therefore, it is recommended to the laundries 1 and 4 that adopt measures in the intention of reducing the temperature, providing, larger thermal comfort to the workers.

\subsubsection{Evaluation of the acoustic environment}

The noise levels found at the four laundries were, respectively: $84 \mathrm{~dB}$ (skilark) e $86.9 \mathrm{~dB}$ (drying); $82.1 \mathrm{~dB}$ (skilark) $84.4 \mathrm{~dB}$ (drying); $72.3 \mathrm{~dB}$ a $89 \mathrm{~dB}$; $71.9 \mathrm{~dB}$ a $91.6 \mathrm{~dB}$. The noise level recommended by NR-15 is of up to $85 \mathrm{~dB}$.

With the data it is possible to notice, therefore, that just in the laundry 2 the noise level didn't cross the established limits for NR-15 of $85 \mathrm{~dB}$, for a daily 
exhibition of eight hours, being suggests like this use of protecting headphones, or dampers, in the intention of minimizing the effects caused by the noise.

According to Meira (2004), the acting in the work is influenced considerably by the exhibition to the noise, besides being a possible cause of pathological alterations, mainly in the hearing apparel. Because of that, it is necessary to consider the frequency of emission of the noise, the resonant pressure and the time of exhibition.

\subsubsection{The researched workers' lifestyle}

The workers' lifestyle was analyzed, the aspects that could influence the precocious functional aging standing out, as feeding, consumption of alcoholic drinks and cigarette. In what it concerns to the consumption of alcoholic drink and cigarette, $54.5 \%$ of the workers of the laundries 1 and 2, they admitted to consume alcoholic drink. The drink more consumed was the beer, and the consumption felt in the weekends. As for the cigarette use, it was verified that $9 \%$ smoked.

In the laundry $3,22.58 \%$ of the workers were smoking, and $67.74 \%$ made use of alcoholic drinks at least once a week. Meanwhile, in the laundry 4, only $12.5 \%$ of the workers manifested to possess that habit, however, $81.25 \%$ said to consume alcoholic at least once a week, being beer and white rum the drinks more mentioned.

According to Fischer et al. (2005), the adoption of no-healthy life habits as the consumption of alcohol and tobacco, as well as the bad life conditions, they can worsen, as well as to accelerate, the occurrences that concern the capacity loss for the work. In that sense, the analyzed employees were susceptible the that loss in function of the noticed habits.

Regarding the workers' of the laundries 1 and 2 feeding, it was discovered that all the workers of the laundry 1 did a meal as soon as they woke up, being this composed by coffee with milk or pure coffee. Besides, $87.5 \%$ ate a bread with butter and a worker said that he didn't eat bread, but a salty one in the shopping center, while it awaited the bus. Almost all the workers of the laundry 2 took breakfast, tends the great majority told to like to take coffee and, or, milk and to eat a bread with butter.

In relation to breakfast, $80.64 \%$ of the workers of the laundry 3 said to eat bread with butter and to take coffee with milk, while $19.36 \%$ told that in breakfast just ate fruits and they drank coffee.
In the laundry $4,50 \%$ of the workers said to be this composed by coffee, bread and butter. Already $12.5 \%$ told to be the breakfast composed by fruits, milk and bread, while $18.75 \%$ said to eat in breakfast, coffee with milk and cookies. Only $6.25 \%$ told to just take a coffee cup in the breakfast, also $6.25 \%$ told to be breakfast composed by cake, bread, butter, fruit, milk and cookie, already $6.25 \%$ said to just eat cake and to take vitamin of fruits.

Concerning the lunch, all the workers consumed rice, bean and salad daily and, except for two employees, they ate meat daily. The laundry 1 supplied lunch to the employees, being served rice daily, bean, meat and some types of salads. The employees of the laundry 2 had as alimentary base in the lunch the rice and the bean; two employees said not to eat green vegetables and vegetables, for the fact of they appreciate not these types of foods. A worker said to like a lot of green vegetables, for always not having money to buy meat and green vegetable, preferred to buy the meat instead of the green vegetable, since daughter preferred the meat; another interviewee said that she ate rice and bean daily, and when was able to bought meat and, or, green vegetable. Unlike the laundry 1, the laundry 2 didn't supply lunch to the employees, being necessary that the employees brought house lunch pail. To the they arrive at the work place, the workers left the lunch pail in the dining hall, and they went back to catch in the schedule stipulated for the same.

Regarding the lunch, in the laundry 3 all the workers told to be the same composed by rice, bean, meat and salad, except for an employee that was considered vegetarian and it didn't consume meat. The laundry didn't supply lunch to the workers. Some paid an amount a month to a secretary of the section for purchase of the foods, then the laundry made available cooks and the place for cooking, that was precarious. In that way, most of the workers ate lunch at the work place. The workers that didn't pay that tax brought the house lunch, in lunch pails.

The ones that paid the defined amount for the cooking of the meal were shown unsatisfied with the meal served by the laundry, telling that considered the price no in keeping with the quality of the served meal.

In the laundry $4,93.75 \%$ of the workers told to be the lunch composed by rice, bean, meat, salad and tipical food of the state of Minas Gerais (angu). This food is prepared using water, corn and sometimes salt), and the meat type and of salad it varied, from one day to the next. Only $6.25 \%$ said to be the lunch 
composed by rice, bean, meat, angu, except for the salad. The responsible workers for the shift of the morning brought the house lunch in lunch pails and they made the meal in the laundry.

In relation to the snack of the afternoon, all the workers of the laundry 1 said that drank coffee and they ate bread with butter. As two interviewees, when possible they liked to eat little cake or bread with meat. Most of the interviewees of the laundry 2 told to have a snack in the laundry in the days in that worked. This laundry, in the period of the afternoon, offered to the workers bread with butter, juice or coffee. Some workers reverse-shouted of the flavor of the juice, saying that it was too "watery". It is done necessary to stand out that a lot of workers to the they emit opinions concerning the snack, they revealed dissatisfaction and resentment in relation to the laundry.

As for the snack of the workers' of the laundry 3 afternoon, $90.33 \%$ said to be most of the time the snack the same of breakfast, while $9.67 \%$ said not to possess the habit of doing snacks in the period of the afternoon. In relation to this snack in the laundry 4, $56.25 \%$ of the workers said to be same to breakfast, only $6.25 \%$ said not to do the snack of the afternoon, $12.5 \%$ said to eat in it slashes of the afternoon, bread and juice, also $12.5 \%$ said to just take pure coffee, while $12.5 \%$ consumed in the snack of the afternoon, coffee with milk, while only $6.25 \%$ said not to do the snack of the afternoon.

It was requested the workers that said what ate at night. Most of the interviewees of the laundry 1 answered that possessed the habit of having dinner, two workers didn't have dinner; one drank a glass of milk and the other drank coffee and ate a cookie or pizza. Most of the interviewees of the laundry 2 said that had dinner (rice, bean, salad and meat), while the ones that didn't have dinner the habit of eating cookie, bread or cake, and drinking coffee, milk, juice or tea. A worker said that ate fast food like, as pizza, hamburger etc., and took juice or soft drink, while other employee said that was not every day that has what to eat at night, but when she had conditions bought bread and she ate with butter.

In the laundry $3,74.19 \%$ said that ate in dinner basically what ate in the lunch, meat of different kinds and green vegetables. Already $25.80 \%$ said not to possess the habit of having dinner and, yes to do snacks in the period of the night, usually composed by sandwiches, juice, milk and fruits. The result of the laundry 4 if it assimilated to the of the laundry 3, where $75 \%$ of the interviewees told to be same to the lunch, $6.25 \%$ said to just eat pasta, other $12.5 \%$ of the workers said to substitute dinner for other snack, being this composed by bread with meat and juice, while $6.25 \%$ told to be dinner basically equal to the lunch, except for the substitution of the meat for eggs.

It is necessary to consider that a balanced feeding physical activities of extreme importance with respect to the aging process, be physical or mental, besides a good feeding of the nutritional point of view can prevent diseases like anemia, osteoporosis, arthritides, etc.

\subsubsection{Interfaces of the health with the workers' work: characteristics and perceptions}

Tried to be analyzed the employees felt headaches frequently. Like this, it was detected that $50 \%$ of the workers of the laundry 1 said feel not headaches; but $37.5 \%$ they affirmed to feel headache at least once a week. In the laundry 2, 50\% argued that sometimes had headaches, $21.4 \%$ had headaches at least once a week, and one employee said feel headache everyday.

In the laundry $3,67.74 \%$ said not to feel, already $32.25 \%$ alleged to feel headaches at least once a week. The workers mentioned to feel headaches due to the high temperatures and to the present noises in the laundry.

As for the occurrence of headaches, in the laundry $4,75 \%$ said that didn't feel, $12.5 \%$ felt headaches at least once a week, and $6.25 \%$ felt everyday and, $6.25 \%$ affirmed that, they sometimes felt headaches

Berro (s.d.) it emphasizes that the headache is one of the symptoms of the worker unsatisfied with your work, besides pains in the backs, irritation, allergies, muscular pains, fatigue, anxiety, anguish, irritation, depression, insomnia, stress, gastric disturbances etc. Finally, the worker victim of the unsatisfied, most of the time possessed low capacity for the work, and this ends up generating this phenomenon of the pain.

Already in relation to the interviewees' of the laundries perception as for health, the data revealed that $50 \%$ of the workers of the laundry 1 felt that health was in the same way that in the previous year, in other words, didn't have gets better, while $37.5 \%$ felt that were with the better health in the year of the research than in the previous year. However, it is worth to highlight that some of the employees that affirmed that if they felt better in the year of the research in relation to the previous year they related this improvement in the health to the vacations that 
were granted to them in the end of the year. The workers that said that if they felt better in the year of the research than in the previous year they presented age between 24 and 36 years old, while the employees that told feel her the same ones, in other words, they didn't verify any alteration in health in relation to the previous year, they possessed age varying from 20 to 47 years old. It was obtained as answer in the laundry 2 concerning the analyzed aspects the following ones percentile: $14.3 \%$ of the workers with 25 and 30 years felt worsen than last year, $42.9 \%$ felt the same ones, that is, they didn't relate health with any improvement nor it worsens; $35.7 \%$ felt get better than last year; and a 23 year-old worker said that it had gotten sick with more frequency. Concerning the relationship between age and perception of the health, it was detected that the workers that said that noticed better health in the year of the research possessed age between 34 and 59 years old, while the ones that said that didn't feel alteration in health possessed age between 35 and 46 years old. Monteiro (1999) it argues that older workers are healthier than younger workers; these present a larger number of diseases than the oldest. In this aspect the data of the referred section corroborate with the mentioned research.

The workers of the laundry 3 , answered in majority, $70.96 \%$, that if they felt the same in relation to last year, $22.58 \%$ said to feel that health was better than last year. When investigated on the reason if they felt better, the workers answered that in relation to the previous year them if they felt stronger and they got less sick. Only $3.22 \%$ of the workers felt worsen than in the previous year and $3.22 \%$ felt that got sick with more frequency.

Regarding the laundry 4, the workers in majority $(81.25 \%)$, they answered that felt the same in relation to the previous year. $6.25 \%$ said if they feel worse than in the previous year, and $6.25 \%$ mentioned that, in relation to last year they felt that got sick with more frequency. Only $6.25 \%$ noticed that health was better in relation to the previous year.

Martinez and Latorre (2006) said that all of the subjects of health appear in association with the capacity for the work, and as better the health condition, larger the capacity for the work. In that way, the health is shown as factor that adult exercises impact on this variable. However, the health is considered the factor that exercises the largest impact about this capacity.

In what refers to diseases, asked the interviewees of the laundries 1 and 2, which were the diseases that they possessed: $36,3 \%$ answered that didn't possess any disease; an employee told to have "skin disease", specifically mycosis, that he believes to have acquired at the laundry. A worker emphasized that it possessed disease of the blood (anemia); and 50\% of the workers emphasized that had muscle-skeletal possessions (excessive pain in the column and constant pain in the inferior members and superiors, syndrome of the shift of the weed bilateral, osteomelite etc.); some workers that affirmed to have muscleskeletal problems commented on although they possessed digestive problems (pain in the stomach) and in the breathing treatment (sinusitis) and frequent headache.

In the laundry 3, 96\% said not to possess any disease, while $16.12 \%$ said to suffer of hypertension, and $12.88 \%$ mentioned other diseases like of the skin and muscle-skeletal. Regarding the laundry $4,75 \%$ of the workers said possess not any disease, already $18.75 \%$ told to suffer of arterial hypertension, and only $6.25 \%$ said muscle-skeletal diseases.

Asked the workers of the laundries 1 and 2, if in two years, starting from the year of the research, they would be capable to do everything that do today: $22.72 \%$ answered that it was quite unlikely, $31.81 \%$ were not very right and $40.9 \%$ believed that it was quite probable. Although $40.9 \%$ have demonstrated certainty, it is believed that the uncertainty of most is linked to the conditions of health and the current lifestyle.

Already $77.41 \%$ of the workers in the laundry 3, they said that it was quite probable that were capable to accomplish the same work in two years, already $19.35 \%$ said that were not very right on that subject, only $3.22 \%$ said to be unable. While in the laundry 4 , all the workers said that it was quite probable that were capable to accomplish the same work after two years.

In relation to swelling in the feet and in the legs, $86.36 \%$ of the workers of the laundries 1 and 2, they didn't possess this problem type. However, 13.6\% told that their feet and legs always dilated at the end of the day of work. It is believed that the swelling is due to the work accomplished for 2 hours considering the position standing, since the workers that alleged swelling in the inferior members belonged to the laundry 2, and the shift work adopted by this laundry was the 12 hours for 36 hours.

The workers of the laundry 3 said not to possess that problem, only $3.22 \%$ said to feel that symptom in the end of the day of work. In the laundry $4,2.5 \%$ of the workers said that the feet were swollen in the 
end of the day of work. Already in relation to the hands, $100 \%$ of the workers answered that these didn't dilate with easiness.

Concerning tingling, $54.5 \%$ of the workers of the laundries 1 and 2, they emphasized to feel frequent tinglings in the members, being this worse at the end of the day work. It is worth to stand out although $50 \%$ of the respondents pointed out that the tingling was frequent in the superior members and the other $50 \%$ argued that the tingling was frequent in the inferior members. During the visits it was possible verified that, the workers of the laundries accomplished the whole standing work, executing great physical efforts, in inadequate and uncomfortable positions for the body. Besides, those people's work obeyed an accelerated rhythm, should be emphasized that it is not just needed physical effort, but also of great mental effort, because any decision no correct assumed by the same during the work can result in a work accident.

Of the workers of the laundry 3,70.96\% said not to feel tingling in the inferior and superior members, however, they told to feel pains sometimes at the end of the day of work. Other $29.63 \%$ of the workers manifested to have that sensation of so much tingling in the inferior members as superiors. During the visit to the laundry, it was verified that there was not a space for the workers' rest and that the same ones worked all the day in standing position. Just some workers possessed banks for rest. Besides, all the workers carried the clothes at least in some moment of work day, being dries or wet, and that can cause pains, swellings or tinglings.

In the laundry $4,37.5 \%$ said to feel tingling in the inferior and superior members in some occasions. During the visit to the laundry, it was possible to observe that the workers stayed for a long time standing, besides they carry big amount of dry and wet clothes, what could cause a lot of effort in the superior members.

Identified that, $50 \%$ of the workers of the laundries 1 and 2, they presented problems of blood circulation. In the laundry $3,25.80 \%$ presented that problem being a male one. While in the laundry $4,25 \%$ said that possessed blood circulation.

Before a work that obeys an accelerated rhythm, accomplished during six or eight hours standing, is considered that the employees will feel pain in the members, mainly in the inferior, and they will still be able to have as consequence problems of blood circulation, as verified in the reports.
It was looked for to investigate the workers' muscular force, once this implicates deterioration of the mobility and of the individual's functional capacity. Was that $50 \%$ of the participants of the laundries 1 and 2, they noticed that muscular force was decreased. As for the employees' age group that told decrease in the muscular force, identified that most possessed age between 35 and 47 years old. Sinhoreli (s.d.) it emphasizes that the pick of the force in the human being is reached between the 20 and 30 years old. After that period has beginning the gradual and progressive reduction, becoming clinically perceptible starting from the 60 years.

In the laundry $3,45.16 \%$ of the workers told us, which haven't changes in relation to the muscular force in the last years, however, $35.48 \%$ said had an increase in the muscular force and only $16,12 \%$ manifested to have sense a decrease of the muscular force.

The workers of the laundry 4, in majority $(62,5 \%)$, mentioned that in last years muscular force didn't modify $18.75 \%$ felt that muscular force increased, and $18.75 \%$ said that muscular force decreased.

This study looked for to identify the perception that the worker had of visual sharpness. It was verified that $59 \%$ of the workers of the laundries 1 and 2 , they considered that vision presented problems, being the most frequent complaints related visual impairment (tired vision), dimmed and, to the difficulty to see small letters and those that were far. As for the problems in the vision told by the workers of the laundry was more appealing to the workers with age below 44 years old. According to Odebrecht (2002), dysfunction in the vision for far away is only expected starting from the 45 years. It is important to emphasize that a worker associated irritation in the eye to a product used at the laundry.

In the laundry 3,41.93\% manifested not identify any problem regarding the visual sharpness, considering the same if found in great state, $29.03 \%$ said to feel the most tired vision, $25.80 \%$ manifested to feel difficulties to read small letters and $3.22 \%$ presented difficulties to see information that were far.

While in the laundry $4,18.75 \%$ of the workers said that felt great vision, $25 \%$ manifested that the vision was more tired, $12.5 \%$ said to feel difficulties to see far, to read small letters and that the "view was more tired", $12.5 \%$ also told to feel difficulties just to see far, $12.5 \%$ manifested difficulties to read small letters, $12.5 \%$ told to have difficulties for small letters and that the "view is more tired", and $6.25 \%$ said to feel difficulties to read small letters and to see far. 
In what it concerns at the hours of the workers' sleep for day/night, it was discovered that $75.0 \%$ of the workers of the laundry 1 , they slept from six to seven hours. In the laundry 2 , it was verified that, of the 14 interviewees, two slept from four to five hours per night, five slept up to six hours, five slept up to seven hours, one slept from seven to eight hours and one slept more than eight hours. Cronfili (s.d.) emphasizes that a person should sleep from seven to eight hours per night, because the privation of the sleep can commit the production certain hormones considered as fundamental for the organism has a good function.

It is stood out that, $71.4 \%$ of the respondents no have insomnia, however, $12.5 \%$ of the workers of the laundry 1 and $28.6 \%$ of the laundry 2 affirmed have problems to sleep. In the laundry 3,29.03\% workers slept more than eight hours a day, $22.58 \%$ slept from seven to eight hours, $22.58 \%$ slept up to seven hours a day, $16.12 \%$ slept up to six hours and $16.12 \%$ slept from four to five hours a day.

Already in the laundry $4,12.5 \%$ of the workers slept up to six hours for day/night, $6.25 \%$ slept from four to five hours for day/night, $31.25 \%$ slept up to seven hours, $43.75 \%$ slept from seven to eight hours and $6.25 \%$ slept more than eight hours for day/night. In the laundry 3 there was a worker that told to suffer of insomnia. Martins (s.d.) tells that alterations in the sleep can bring modifications as reductions in the efficiency of the cognitive process, deficit of memory, metabolic alterations and hypertension.

As for the practice of physical activities, it was verified that $63.6 \%$ of the interviewees in the laundries 1 and 2, they didn't practice any kind of physical activity. However, $36.4 \%$ affirmed that made physical activity, being the soccer and walk.

In the laundry 3 , it was verified that $48.38 \%$ of the workers practiced physical activities at least three times a week. Among the physical activities, the more practiced were walked, soccer and body building. Already in the laundry $4,75 \%$ of the workers practiced physical activities at least twice a week, being the activities, for example, walk and soccer.

Study developed by Raffone and Hennington (2005) it shows that workers that practice some physical activity have more probability of presenting good work capacity in relation the others which that don't practice any activity.

Concerning the variation of the temperature, it was detected that workers of the laundries 1 and 2, reacted to in a very different way, because $87.5 \%$ of the workers of the laundry 1 said to react well, while
$71.4 \%$ of the workers of the laundry 2 said not to react well to the temperature variation and, before this, presented several problems of health, for example, sinusitis.

In the laundry $3,83.87 \%$ of the workers said to get if it adapts well to the temperature variation, while $19.12 \%$ said be not capable to adapt well these variations. In the laundry 4 , it was verified that $87.5 \%$ of the workers got if it adapts and 12.5\% manifested opinion contrary about this fact.

It was looked for to also discover the workers' perception as for memory and reasoning: $62.5 \%$ of the workers of the laundry 1 didn't feel any difference as for the worsening or it gets better in what refers to the reasoning, as well as to the memory; $25 \%$ they considered that the memory got better, and the reasoning worsened. In the laundry $2,42.9 \%$ of the respondents, with age between 25 and 36 years old, they considered that memory worsened, while other $42.9 \%$ didn't feel any difference. In relation to the reasoning, $42.9 \%$ of the respondents with age group between 25 and 58 years old considered that reasoning worsened, for $28.6 \%$ there was gets better.

As for the reasoning, $67.74 \%$ of the workers in the laundry 3 said not to feel difference in reasoning power, $29.03 \%$ considered that there was an improvement in relation to the previous year, and $3.22 \%$ that there was loss in reasoning power. The worker that told to have had loss, if found in an age group from 20 to 30 years old, showing that the age was not the only factor that interferes in that variable.

Already in the laundry $4,43.75 \%$ of the workers said not to feel difference in relation to the previous year, already $50 \%$ manifested that the reasoning presented improvements in relation to the previous year.

Regarding the capacity of the workers' memory, in the laundry $3,29.03 \%$ of the interviewees told to have had an improvement in capacity of memory, $58.06 \%$ didn't feel difference in capacity of memory, while $12.90 \%$ felt that the capacity of memory had modified in relation to last year.

It was verified at the laundry 4 , that $62.5 \%$ of the workers said not to feel differences in relation to memory, $31.25 \%$ that the memory had presented an improvement when compared to the previous year, $6.25 \%$ felt worsening in relation to memory.

Asked the workers like them evaluated general acting. In the laundry 1, two workers of 20 and 24 years old, respectively, they didn't know to answer this question; a 25 year-old worker said that was long more to learn new things; a 36 year-old worker said that if felt more tired; two workers of 46 and 47 years 
old, said, now were long more to find solutions for the problems and also to learn new things; a 28 yearold employee said that if felt more tired and that was long to find solution for the problems; and, finally, a 21 year-old worker said that he had difficulty to find solution for the problems. Therefore, it is verified that the largest complaints as for the current general acting in the laundry 1 referred to the difficulty to find solutions for the problems and to learn new things. In agreement with Santana apud Odebrecht (2002), the decline of a individual capacity has beginning to the 30 years old.

On the other hand, in the laundry 2, five workers, with ages between 35 and 59 years old, affirmed that didn't feel any difference in acting; a 27 year-old worker told that was long more to learn new things and that the work rhythm increase; three workers with ages between 23 and 34 years old said that if they felt more tired; a 58 year-old worker said that believed that was long more now to learn new things; and four workers, besides if they feel more tired, they considered that the speed of the movements that accomplished has been decreasing.

It was possible to verify at the laundry 3 that most $(35.48 \%)$ of the interviewees it felt that the work rhythm increase. It was also verified that $32.25 \%$ of the interviewees felt more tired due to the work rhythm, while $3.22 \%$ didn't feel any difference as for general acting. It is only $3.22 \%$ told to have more difficulties to learn new things.

Already in the laundry $4,37.5 \%$ said that lately they didn't feel any difference, $12.5 \%$ said that the increase work rhythm, but they were more tired and they were long more to learn new thing, $6.25 \%$ answered to be more tired, and that their reactions were slower, but their reactions were slower and that the speed with that accomplished movements had decreased, $6.25 \%$ said be more tired lately, $6.25 \%$ said to be long more to find solutions for problems $6.25 \%$ said to be long more to learn new things, and also $6.25 \%$ told to be more tired lately.

In this subject of the productivity Odebrecht (2002) it detaches that older people have more difficulties to solve problems and this fact interferes in the in the process of socket of decision and in the work rhythm. Considering those aspects mentioned by the author the data in the studied laundries, considering acting and work rhythm reinforces such theory and they evidence that the environment of analyzed work offers strong indications that contributes to the worker's of the section functional aging.

\subsubsection{Analysis of the absenteeism in the researched laundries}

It was identified that the laundry 1 received 280 certificates in the analyzed period, while the laundry 2 received 90 certificates. In the laundry 3 it was possible the access the only to 11 certificates, the others if they didn't find at the laundry. In the laundry 4 there were not registrations as for the absenteeism. As told by the managers being the last registration of the year of 2007 .

Before the collected data, the frequency index, the gravity and the proportion of the time were made calculations lost in agreement with proposed in study Gehring Júnior's et al. (2007), for time, they suggest for evaluation studies of Mendes (1980). In that sense, was at the laundry 1 an index of frequency of four initiate removals for employee in the investigated period and gravity of 5.9 lost days for employee. Besides, the proportion of lost days for the studied period was of $2.9 \%$.

In the laundry 2 , it was possible to discover the index of frequency of 0.73 for employee, the gravity of 7.53 lost days for employee and the proportion of equivalent time to $9.77 \%$. The frequency found at the laundry 3 , it was of 2.45 initiate removals for the workers, while the gravity of 0.41 lost days for worker, and the proportion of lost days was of $0.45 \%$.

They were analyzed and classified the relative data to the certificates through the CID-10 (International Code of Diseases). However, $27.14 \%$ of the certificates presented at the laundry 1 didn't present CID, or when they presented this code didn't match with any another related in the code. It was verified, still, that $19.28 \%$ of the removals were linked to problems osteomusculares, as low lumbar pain, multiple wounds in the ankle, lumbago with sciatica, cervicalgia among others.

In relation to the laundry 2 , it was obtained result very similar to the of the laundry 1 , once the muscular diseases $(16.66 \%)$ they were the largest responsible for moving away the employees of the work, coming in second place the breathing diseases $(15.55 \%)$ concerning the muscular diseases in the laundry 2, it was detected larger prevalence of low lumbar pain, dorsalgia and lumbago with sciatica.

\section{Conclusions}

The laundry environment is an unhealthy environment and that offers risks for the workers. Those 
risks can cause irreversible damages to the workers' health, and, as consequence, the precocious removal of the job market.

As for the lifestyle, identified that the workers' great part was put resistant to the practice of physical activities, as well as to habits of healthy feeding of the nutritional point of view. Besides there being consumption of drunk alcoholic all of the weekends. In this sense, those workers' lifestyle contributes directly to reduce the capacity for the work, what reverts in precocious functional aging.

The work conditions offered to the workers were precarious, because in the laundries they were found high noise levels and temperature.

When considering that the low capacity for the work and their unhealthy conditions of the environment accelerate the functional aging, it was ended that the workers of the analyzed laundries are living that process. Besides the mentioned aspects, the workers were exposed to risks physical, chemical, ergonomic, psychosocial and biological, that associated leave these possibility of exposing to diseases and fatigue. Understands each other, still, that sick worker, or, accident victim has capacity for the work decreased, being this last fact directly related with the process of functional aging.

In this context, it is ended that the process of functional aging is resulted of multiples factors, among which the environment laboral is stood out, in function of the physical wear and tear and of the stress level demanded by the accomplished work, with repercussions on the absenteeism degree and, consequently, about the relationship health, productivity, social life and family of the worker.

Some measured as the adoption of healthy habits, improvements in the quality of the feeding, larger surveillance as for the health condition, an environment of more ergonomic work, the quality in the relationships, besides other aspects that measures can be considered capable to improve the quality of the workers' life and to avoid that the functional aging happens in a precocious way.

\section{Acknowledgement}

The research group realized this study after financial support of National Council of Advice of Research and Technological Development (CNPq).

\section{References}

[1] Andrade. C. B. Envelhecimento e capacidade para o trabalho dos trabalhadores dos serviços de higiene e limpeza de um hospital universitário. 2002. 122 f. Dissertação (Mestrado em Enfermagem) - Universidade Estadual de Campinas, Campinas, 2002.

[2] Berro, D. Qualidade de vida e produtividade. Available on: $<$ http:/www.administradores.com.br/artigos/qualidade de vida e produtividade/14003/>. Access on: 1ำ August 2008.

[3] Couto, H. A. Ergonomia aplicada ao trabalho: o manual técnico da máquina humana. v. 1, Belo Horizonte-MG: Editora Ergo, 1995.

[4] Cronfili, R. T. A importância do sono. Available on: $<\mathrm{http}$ ://www.cerebromente.org.br/n16/opiniao/dormirbem1.html>. Access on: 11 July 2008.

[5] Fiedler, N. C.; Venturoli, F.; Minetti, L. J. Análise de fatores ambientais em marcenarias no Distrito Federal. Rev. Bras. Eng. Agríc. Ambient., Campina Grande, v. 10, n. 3, set. 2006

[6] Fischer, F. M; Borges, N.S.; Rotenberg, L.; LaTorre, M. R. D. de O.; Soares, N. S.; Rosa, P. L. F. S.; Nagai, R.; Landsbergis, P. A (in)capacidade para o trabalho em trabalhadores de enfermagem. Revista Brasileira de Medicina do Trabalho, Belo Horizonte, v. 3, n. 2, 2005.

[7] Gehring Junior, G.; Filho, H. R. C.; Neto, J. D. C.; Ferreira, N. A.; Vieira, S. V.R. Absenteísmo-doença entre profissionais de enfermagem da rede básica do SUS Campinas. Rev. Bras. Epidemiol., São Paulo, v. 10, n. 3, Set. 2007.

[8] Martinez, M. C; LaTorre, M. do R. D. Saúde e capacidade para o trabalho em trabalhadores da área administrativa. Available in: <http://www.scielo.br/pdf/rsp/v40n5/15.pdf>. Access on: June 2007.

[9] Martins, M. M. Qualidade de vida e capacidade para o trabalho de profissionais de enfermagem no trabalho em turnos. Florianópolis: 2002. $85 \mathrm{f}$. Dissertação (Mestrado em Engenharia de Produção) - Universidade Federal de Santa Catarina, 2002.

[10] Meira, L. F. Capacidade para o trabalho, fatores de risco para as doenças cardiovasculares e condições laborativas de trabalhadores de uma indústria metal-mecânica de Curitiba/PR. Curitiba: 2004. 133 f. Dissertação (Mestrado em Engenharia Elétrica) - Universidade Federal do Paraná, 2004.

[11] Mendes, R.; Dias, E. C. Saúde dos trabalhadores. In: ROUQuayrol, M. Z.; Almeida Filho, N. (Org.). Epidemiologia \& Saúde. R. ed. Rio de Janeiro: Medsi, 1999, p. 431-456.

[12] Monteiro, M. S. Envelhecimento e capacidade para o trabalho entre trabalhadores brasileiros. São Paulo: 1999. Tese (Doutorado em Saúde do Trabalhador) - Faculdade de Saúde Publica, Universidade de São Paulo, 1999.

[13\} NR-15 - Atividades e operações insalubres. In: Segurança e medicina do trabalho. São Paulo: Atlas, 2002.

[14] Odebrecht, C. Adequação do trabalho ao trabalhador que envelhece: recursos auxiliares. Florianópolis: 2002. $217 \mathrm{f}$. Tese (Doutorado em Engenharia de Produção) - Universidade Federal de Santa Catarina, 2002.

[15] Pizzatto, E. A saúde bucal no contexto da saúde do trabalhador: análise dos modelos de atenção. Araçatuba: 2002. 110 f. Dissertação (Mestrado em Odontologia Preventiva e Social) - Faculdade de Odontologia, Universidade Estadual Paulista, 2002.

[16] Raffone, A. M.; Hennington, E. A. Avaliação da capacidade funcional dos trabalhadores da enfermagem. Rev. Saúde Pública, São Paulo, v. 39, n. 4, p. 669-676, 2005.

[17] Sinhorelli, D. A perda da força muscular. Available in: $<$ http://www.tudoperto.com.br/destaque/fitness.html $>$. Access on: July 2008. 